\title{
0920. Cerebrovascular autoregulation in normotensive hypovolaemia: a study combining lower body negative pressure and MRI
}

\author{
SC Beards ${ }^{*}$, S Brodie ${ }^{2}$, J Cain², LM Parkes², A Jackson² \\ From ESICM LIVES 2014 \\ Barcelona, Spain. 27 September - 1 October 2014
}

\section{Introduction}

Previous studies using transcranial Doppler sonography have suggested that cerebral circulation is preserved relative to cardiac output during normotensive hypovolaemia (NTH). We have further investigated the cerebral autoregulatory responses to hypovolaemia using using MRI measurements of total cerebral blood flow combined with graded levels of lower body negative pressure (LBNP) to induce steady state central hypovolaemia.

\section{Methods}

11 healthy male volunteers (21-24 years) underwent MRI scanning with their legs and torso within a LBNP chamber; phase contrast angiography based flow measurements (MRI-PCA) were acquired at $10 \mathrm{mmHg}$ increments from baseline, to $-50 \mathrm{mmHg}$. Measurements were made through the carotid and vertebral arteries to measure total cerebral volume flow (CBVF) and through the ascending and proximal descending aorta to measure cardiac output (CO).

\section{Results}

At low levels of LBNP $(\leq-20 \mathrm{mmHg})$ decrease in CBVF was directly proportional to the decrease in $\mathrm{CO}$ (Figure 1). Between LBNP of $-20 \mathrm{mmHg}$ and $-40 \mathrm{mmHg}$ there was a relative maintenance of CBVF in relation to cardiac output $(\mathrm{P}<0.05)$ in keeping with classic, pressure mediated, cerebrovascular autoregulation. LBNP of $-50 \mathrm{mmHg}$ produced a decrease in CBVF of $65.5 \%$ decrease $(\mathrm{P}<0.01)$ in keeping with a $63.6 \%(\mathrm{P}<0.01)$ decrease in $\mathrm{CO}$.

University Hospital of South Manchester, Acute Intensive Care Unit, Manchester, UK

Full list of author information is available at the end of the article

\section{Conclusions}

These findings demonstrate a correlation between decreases in $\mathrm{CO}$ and CBVF during normotensive hypovolaemia $(\mathrm{NTH})$, which is in disagreement with previous studies using transcranial Doppler to measure CBVF. The findings do not support previous descriptions of relative sparing of CBVF due to compensatory reductions in cerebrovascular resistance in response to $\mathrm{NTH}^{1}$. This difference is likely to reflect the different methods of cerebral blood flow measurement. MRI-PCA allows direct volume flow measurements from the carotid and basilar arteries whereas TCD uses flow velocity in the middle cerebral arteries as a surrogate of volume flow. This

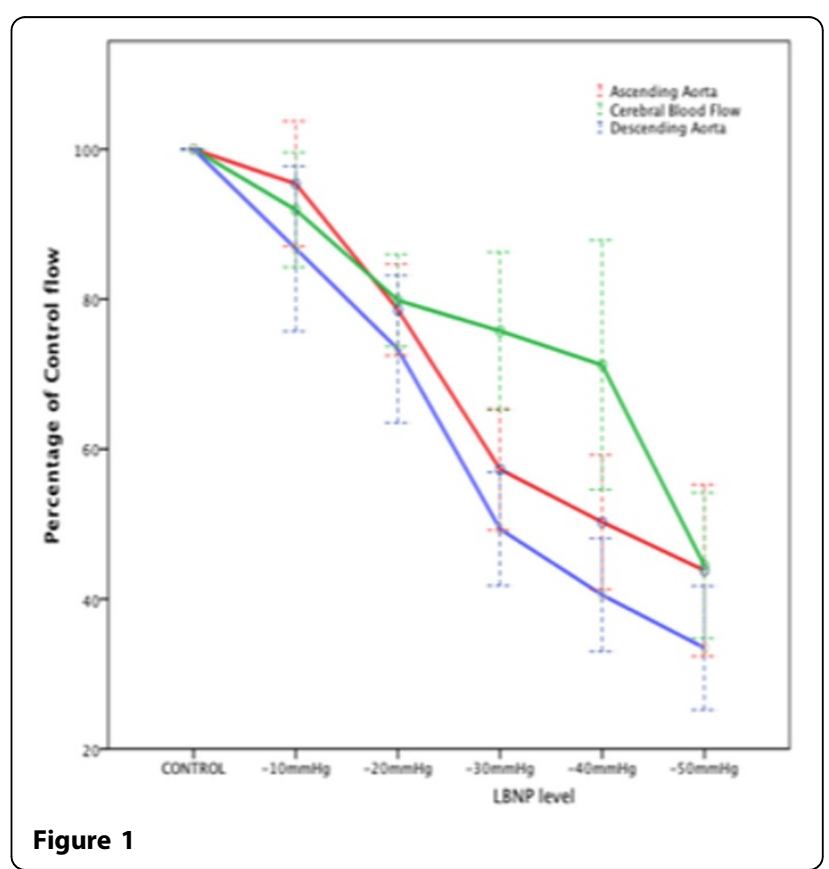

(c) 2014 Beards et al; licensee Springer. This is an Open Access article distributed under the terms of the Creative Commons Attribution License (http://creativecommons.org/licenses/by/2.0), which permits unrestricted use, distribution, and reproduction in any medium, provided the original work is properly cited. 
potentially important discrepancy requires further investigation to elucidate the mechanisms controlling CBF responses to nth.

\section{Authors' details}

${ }^{1}$ University Hospital of South Manchester, Acute Intensive Care Unit, Manchester, UK. ${ }^{2}$ Manchester University, Wolfson Molecular Imaging Centre, Manchester, UK.

Published: 26 September 2014

\section{Reference}

1. Brown CM, Dütsch M, Hecht MJ, Neundörfer B, Hilz MJ: Assessment of cerebrovascular and cardiovascular responses to lower body negative pressure as a test of cerebral autoregulation. J Neurol Sci 2003, 208:71-8.

doi:10.1186/2197-425X-2-S1-O28

Cite this article as: Beards et al:: 0920. Cerebrovascular autoregulation in normotensive hypovolaemia: a study combining lower body negative pressure and MRI. Intensive Care Medicine Experimental 2014 2(Suppl 1): O28.

\section{Submit your manuscript to a SpringerOpen ${ }^{\circ}$ journal and benefit from:}

- Convenient online submission

- Rigorous peer review

- Immediate publication on acceptance

- Open access: articles freely available online

- High visibility within the field

- Retaining the copyright to your article

Submit your next manuscript at $>$ springeropen.com 